\title{
Conductivity behaviour in novel quasi-solid-state electrolyte based on polyacrylonitrile and tetrahexylammonium iodide intended for dye sensitized solar cells ${ }^{\dagger}$
}

\author{
T.M.W.J. Bandara ${ }^{* 1,2}$, T. Svensson ${ }^{1}$, M.A.K.L. Dissanayake ${ }^{3}$, M. Furlani ${ }^{1}$, W.J.M.J.S.R. Jayasundara ${ }^{4}$, \\ P.S.L. Fernando ${ }^{2}$, I. Albinsson ${ }^{5}$ and B.E. Mellander ${ }^{1}$ \\ ${ }^{1}$ Department of Applied Physics, Chalmers University of Technology, Sweden. \\ ${ }^{2}$ Department of Physical Sciences, Faculty of Applied Sciences, Rajarata University of Sri Lanka, Mihintale. \\ ${ }^{3}$ Institute of Fundamental Studies, Hantana Road, Kandy. \\ ${ }^{4}$ Postgraduate Institute of Science, University of Peradeniya, Peradeniya. \\ ${ }^{5}$ Department of Physics, University of Gothenburg, Gothenburg, Sweden.
}

Submitted: 07 September 2012; Accepted: 14 February 2013

\begin{abstract}
The conduction of iodide ions in gel polymer electrolytes and the performance of dye sensitized solar cells containing such an electrolyte can be enhanced by incorporating a salt having a bulky cation. In this work, polyacrylonitrile (PAN) and $\mathrm{Hex}_{4} \mathrm{~N}^{+} \mathrm{I}^{-}$based gel electrolytes with ethylene carbonate and propylene carbonate as plasticizers have been studied. The variation of conductivity and molar conductivity with salt concentration has been discussed in order to understand the mechanism of iodide ion conductivity in this system. Out of the various compositions studied, the electrolyte containing $120 \%$ salt with respect to weight of PAN showed the highest conductivity, $2.0 \times 10^{-3} \mathrm{Scm}^{-1}$ at $25^{\circ} \mathrm{C}$ and a glass transition at $-102.3{ }^{\circ} \mathrm{C}$. The electrolytes exhibit predominantly ionic behaviour and because of the bulky cation a negligible cationic transport is shown. A quasi-solid-state dye sensitized solar cell was fabricated employing the optimized gel electrolyte. This cell showed an energy conversion efficiency of $3.1 \%$ and a short circuit current density of $8.1 \mathrm{mAcm}^{-2}$ under irradiation of $1000 \mathrm{Wm}^{-2}$.
\end{abstract}

Keywords: Dye sensitized, gel polymer electrolyte, ionic conductivity, molar conductivity, polyacrylonitrile, solar cell.

\section{INTRODUCTION}

The widely used energy resources today are fossil fuels and nuclear energy. However, the excessive consumption of fossil fuels during the last few decades and uneven distribution of fossil fuels in the world have lead to serious environmental problems, primarily due to the emission of green house gases together with many other pollutants, while nuclear power is faced with safety issues and problems associated with radioactive waste disposal (Abbott et al., 2010). In order to overcome these problems, the development of renewable and clean energy sources is important. Solar energy provides a good alternative as a renewable energy source and the use of solar cells provides a convenient method to convert solar energy directly into electricity. However, the high production cost of present day Si-based solar cells has become an obstacle to widespread utilization of solar cells. Therefore, the development of low cost, dye sensitized solar cells (DSSCs) has a great potential to offer a reliable method to convert solar energy to electricity (Chiba et al., 2006; Li et al., 2006; Hagfeldt et al., 2010). Although liquid electrolyte based DSSCs have efficiencies around $10 \%$, they have several drawbacks such as electrolyte leakage, need for robust sealing, problems of electrode corrosion and of stability in the long run. In order to overcome these drawbacks, solid electrolyte based and gel electrolyte based DSSCs are currently being developed (Wu et al., 2006; Bandara et al., 2010a). However, the performance of DSSCs needs to be improved further in order to make them commercially viable devices. In this regard, the improvement of both the photo-electrode and the electrolyte is important in order to enhance the performance. This study is focused on the preparation of a dependable gel polymer electrolyte to be used in DSSCs and the understanding of its ionic transport properties.

\footnotetext{
* Corresponding author (awijendr@yahoo.com)

$\dagger$ Part of this work has been presented at the Solar Asia 2011 International Conference held on $28-30$ July 2011 at the Institute of Fundamental Studies, Kandy.
} 
Although synthetic polymers have been used as structural materials and electric insulators for a long time, it is only during the past few decades that they have emerged as ionically conducting materials (Wright, 1975; Armand et al., 1979). Due to numerous advantages inherent in synthetic polymers, lithium ion conducting polymers are being developed as electrolyte membranes in lithium rechargeable-batteries and iodide ion conducting polymers are being developed as electrolytes for dye sensitized photo-electrochemical (PEC) solar cells. Out of these polymer electrolytes, solid polymer electrolytes such as those based on polyethylene oxide (PEO) complexed with suitable ionic salts still have low ionic conductivities and therefore, need to be further optimized in order to obtain electrolytes with reasonably high ionic conductivity to be used in lithium batteries or PEC solar cells. However, quasi solid or gel electrolytes, formed by incorporating the host polymer, the ionic salt and plasticizers such as ethylene carbonate (EC) and propylene carbonate (PC) offer a compromise between a solid electrolyte and a gel electrolyte. These gel electrolytes possess ionic conductivities close to their liquid counterparts and superior mechanical properties compared to liquid electrolytes.

Various host polymers and plasticizers have been incorporated with different iodide salts in order to develop gel polymer electrolytes intended for PEC solar cells (Ileperuma et al., 2004; Ileperuma et al., 2008; Bandara et al., 2010a, c). The reports on incorporation of different alkaline metal iodides (MI) $(\mathrm{M}=\mathrm{Li}, \mathrm{Na}$, $\mathrm{K}, \mathrm{Cs}$ ) in PAN based (Tennakone et al., 1999) and polyethylene oxide (PEO) based (Shen et al., 2008) polymer electrolytes for PEC solar cells are of interest since the effect of changing the size of the cation on the performance of the electrolyte and solar cells have been studied. The study on electrolytes containing PAN have shown that the short circuit photocurrent density $\left(J_{\mathrm{SC}}\right)$ enhances with the increasing size of the cation $\left(\mathrm{M}^{+}\right)$ for $\mathrm{Li}, \mathrm{Na}, \mathrm{K}$ and $\mathrm{Cs}$. This can be understood because the $J_{\mathrm{SC}}$ depends on the mobility of iodide ions, which is enhanced when the cation size is large (Tennakone et al., 1999). From these studies it is clear that the conductivity of iodide ion conducting gel polymer electrolytes and the performance of DSSCs containing such electrolytes can be enhanced by incorporating a salt containing a bulky cation compared to the iodide ion. Hence, for this purpose quaternary-ammonium iodides are appropriate candidate materials.

The iodide ion $\left(\mathrm{I}^{-}\right)$conductivity contribution to the overall ionic conductivity of the electrolyte in a DSSC is a major factor, which determines the $J_{\mathrm{SC}}$ and the efficiency of the solar cell. This is because the iodide ion, while participating in the redox reaction also shuttles between the photo-electrode and the counter electrode. Quarternary ammonium salts such as $\mathrm{Pr}_{4} \mathrm{NI}, \mathrm{Bu}_{4} \mathrm{NI}$ and $\mathrm{Hex}_{4} \mathrm{NI}$ are therefore used as ionic salts in DSSC electrolytes.

Polyacrylonitrile (PAN) based gel polymer electrolytes have been reported to have reasonably good ionic conductivities and they have been used in quasi solid-state PEC solar cells (Ileperuma et al., 2004; Ileperuma et al., 2008; Bandara et al., 2010a). In PAN based gel electrolytes, it is generally believed that the electrolytic solution formed by dissolving the ionic salt in EC/PC is 'trapped' in cages formed by the PAN polymer matrix yielding higher ionic conducti vities. Tetrapropylammonium iodide $\left(\mathrm{Pr}_{4} \mathrm{~N}^{+} \mathrm{I}^{-}\right)$has been used with PEO and PAN host polymers and reasonably good cell performance has been reported, reaching about $3 \%$ overall cell efficiency for the latter system (Dissanayake et al., 2002; Ileperuma et al., 2004) DSSCs containing an electrolyte composed of PAN and tetrabutylammoniumiodide $\left(\mathrm{Bu}_{4} \mathrm{~N}^{+} \mathrm{I}^{-}\right)$salt has also been reported to show very good cell performance (Ileperuma et al., 2008; Ileperuma et al., 2011). However, it appears that there is a lack of reports in the literature on systematic studies on understanding the anion transport behaviour in these polymer electrolytes. In comparison, a large number of studies have been reported on cation transport behaviour in polymer electrolytes intended for use in lithium batteries, electro-chromic devices and other devices (Stephan, 2006).

Ionic radii of $\operatorname{Pr}_{4} \mathrm{~N}^{+}$and $\mathrm{Bu}_{4} \mathrm{~N}^{+}$ions are 4.6 and $5.0 \AA$ respectively, which are significantly larger than those of the alkali-metal ions (Gill, 1979; Shimizu et al., 1999). When the size of the cation increases, it enhances the salt dissociation and the anion transference number leading to high anionic conductivity, which is important for the performance of DSSCs (Ileperuma et al., 2004; Bandara et al., 2010a, b). The radius of the tetrahexylammonium $\left(\mathrm{Hex}_{4} \mathrm{~N}^{+}\right)$ion is larger than that of $\operatorname{Pr}_{4} \mathrm{~N}^{+}$and $\mathrm{Bu}_{4} \mathrm{~N}^{+}$ions, besides $\operatorname{Hex}_{4} \mathrm{~N}^{+}$ions form an ionic liquid structure with the association of iodide ion owing to its large size. To date there are no reports on PAN based gel electrolytes using $\mathrm{Hex}_{4} \mathrm{~N}^{+} \mathrm{I}^{-}$salt. In this study, quasi solid-state (gel) polymer electrolytes were prepared using PAN as the host polymer and $\operatorname{Hex}_{4} \mathrm{~N}^{+} \mathrm{I}^{-}$as the ionic salt and ethylene carbonate (EC) and propylene carbonate (PC) as plasticizers. Besides the optimization of ionic conductivity in the electrolyte by systematically varying the salt concentration, the samples were characterized by using thermal and DC polarization measurements. The concentration dependence of conductivity as well as molar conductivity has been discussed in detail and 
a possible mechanism was suggested. Finally, a quasisolid-state solar cell was fabricated using the optimized electrolyte and the cells were characterized using current voltage curves.

\section{METHODS AND MATERIALS}

PAN, $\operatorname{Hex}_{4} \mathrm{~N}^{+} \mathrm{I}^{-}$, iodine, $\mathrm{EC}$ and $\mathrm{PC}$ all with purity greater than $98 \%$, purchased from Aldrich were used as starting materials. PAN and $\mathrm{Hex}_{4} \mathrm{~N}^{+} \mathrm{I}^{-}$were vacuum dried for $24 \mathrm{~h}$ in a vacuum oven at $50{ }^{\circ} \mathrm{C}$ prior to use. For preparing the electrolyte samples, the weights of PAN $(0.10 \mathrm{~g})$, EC $(0.40 \mathrm{~g})$ and $\mathrm{PC}(0.40 \mathrm{~g})$ were kept unchanged and the weight of $\mathrm{Hex}_{4} \mathrm{~N}^{+} \mathrm{I}^{-}$was varied in order to determine the optimum composition giving the highest conductivity. The amount of iodine in the electrolyte was maintained so that the molar ratio $\operatorname{Hex}_{4} \mathrm{~N}^{+} \mathrm{I}^{-}: \mathrm{I}_{2}$ was $10: 1$. For the electrolyte sample preparation, the selected compositions of chemicals were heated to about $80^{\circ} \mathrm{C}$ and stirred for a few minutes until a homogeneous, viscous solution was obtained. The resulting slurry was cast on to a glass plate and pressed by another glass plate in order to obtain a polymer electrolyte film for measurements. The complex impedance measurements were performed using a HP 4292A RF impedance analyzer in the frequency range $10 \mathrm{~Hz}-10 \mathrm{MHz}$ and temperature range of $20-80^{\circ} \mathrm{C}$. Disc shaped electrolyte films of diameter $\sim 10.5 \mathrm{~mm}$ and thickness $\sim 0.5 \mathrm{~mm}$, sandwiched between two polished stainless steel blocking electrodes were used for impedance measurements.

DC polarization tests were carried out at room temperature by sandwiching a disc shaped electrolyte sample between two stainless steel blocking electrodes and alternatively between two iodine non blocking electrodes. The thermal properties of the samples were analyzed using a Mettler Toledo DSC 30 differential scanning calorimeter between $-140{ }^{\circ} \mathrm{C}$ and $100{ }^{\circ} \mathrm{C}$ in consequent heating and cooling cycles with a rate of $10{ }^{\circ} \mathrm{Cmin}^{-1}$.

A $\mathrm{TiO}_{2}$ nano-porous layer was coated on FTO (Solaronix SA) glass having a sheet resistance of $7 \mathrm{ohm} /$ square using Degussa P25 powder. For this layer preparation, $0.5 \mathrm{~g}$ of Degussa P25 powder $\left(\mathrm{TiO}_{2}\right)$ was ground well for $\sim 30$ min with $\sim 2 \mathrm{~mL}$ of $\mathrm{HNO}_{3}(\mathrm{pH}=1)$ in an agate mortar. The resulting colloidal suspension was diluted with $\mathrm{HNO}_{3}(\mathrm{pH}=1)$ to get a $5 \%(w / w)$ solution. It was subsequently stirred overnight at $60{ }^{\circ} \mathrm{C}$ and a $25 \%$ $(w / w)$ mixture was obtained. To this $\sim 0.1 \mathrm{~g}$ of carbowax and a few drops of Triton X 100 (surfactant) were added and mixed well. This colloidal suspension was casted on FTO substrate using doctor blade method to obtain porous $\mathrm{TiO}_{2}$ layers of about $5-10 \mu \mathrm{m}$ thickness after sintering at $450^{\circ} \mathrm{C}$ for $30 \mathrm{~min}$. The $\mathrm{TiO}_{2}$ coated electrodes were immersed in an ethanolic solution of dye sensitizer ruthenium 535-bis TBA (Solaronix SA) while both were hot $\left(\sim 60{ }^{\circ} \mathrm{C}\right)$. After $24 \mathrm{~h}$ absorption, the electrodes were withdrawn from the dye solution and washed with acetone to remove unabsorbed dye and loosely bound $\mathrm{TiO}_{2}$ particles from the dye-coated electrode.

Quasi - solid-state PEC solar cells were fabricated by sandwiching polymer electrolyte films of thickness about $0.1 \mathrm{~mm}$ between the dye-coated $\mathrm{TiO}_{2}$ electrode and a platinum coated glass electrode (mirror type) in the configuration glass/FTO/ $\mathrm{TiO}_{2} /$ dye/electrolyte/Pt/ glass. All the fabricated solar cells were characterized by measuring $I-V$ curves using a computer controlled eDAQ Potentiostat and e-coder under $\sim 1000 \mathrm{Wm}^{-2}$ irradiation (1.5 AM) with a LOT-Oriel $\mathrm{GmbH}$ solar simulator.

\section{RESULTS AND DISCUSSION}

\section{Ionic conductivity}

The conductivity Arrhenius plots for PAN/EC/PC : $\mathrm{Hex}_{4} \mathrm{~N}^{+} \mathrm{I}^{-}$gel electrolyte samples for different PAN : $\mathrm{Hex}_{4} \mathrm{~N}^{+} \mathrm{I}^{-}=100: x$ weight ratios up to $x=120 \%$ are shown in Figure 1. Out of these samples, the highest conductivity is shown for the electrolyte sample containing 120 wt $\% \operatorname{Hex}_{4} \mathrm{~N}^{+} I^{-}$for all the measured temperatures. This corresponds to an electrolyte composition of PAN: EC:PC: $\operatorname{Hex}_{4} \mathrm{~N}^{+} \mathrm{I}^{-}=1: 4: 4: x / 100$ by weight. The subsequent conductivity Arrhenius plots for salt mass fractions from $120-200 \%$ are shown in Figure 2. All the samples shown in Figure 2, which represent high salt concentrations have reasonably good conductivities. However, $120 \%$ and $140 \%$ salt containing electrolytes seem to have slightly higher conductivities especially at low temperatures. The sample with $120 \% \mathrm{Hex}_{4} \mathrm{~N}^{+} \mathrm{I}^{-}$ has an ionic conductivity of $2.0 \times 10^{-3} \mathrm{Scm}^{-1}$ at $25^{\circ} \mathrm{C}$ and $2.9 \times 10^{-3} \mathrm{Scm}^{-1}$ at $50^{\circ} \mathrm{C}$. The conductivity variation with inverse temperature shows more or less Arrhenius behaviour within the measured temperature range. Hence, the activation energy $E_{\text {a }}$ could be calculated by fitting the data to the Arrhenius equation.

$$
\sigma T=B \exp \left(-\frac{E_{\mathrm{a}}}{k T}\right)
$$

where, $B$ is the pre-exponential factor, $E_{\mathrm{a}}$ the activation energy, $k$ the Boltzmann constant, and $T$ the absolute temperature. The fitted curves to the Arrhenius equation are also shown in Figure 1 for samples containing less than $120 \% \operatorname{Hex}_{4} \mathrm{~N}^{+} \mathrm{I}^{-}$. 


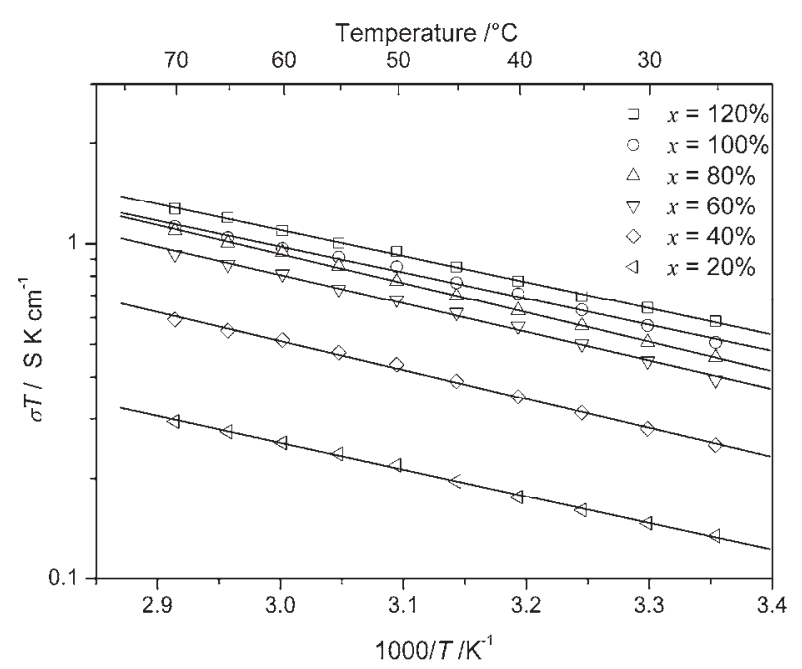

Figure 1: $\sigma T$ vs 1000/T for PAN/EC/PC electrolytes containing $x$ wt $\%$ of $\mathrm{Hex}_{4} \mathrm{~N}^{+} \mathrm{I}^{-}$with respect to PAN mass fraction. Fitted lines to the Arrhenius equation are also shown.

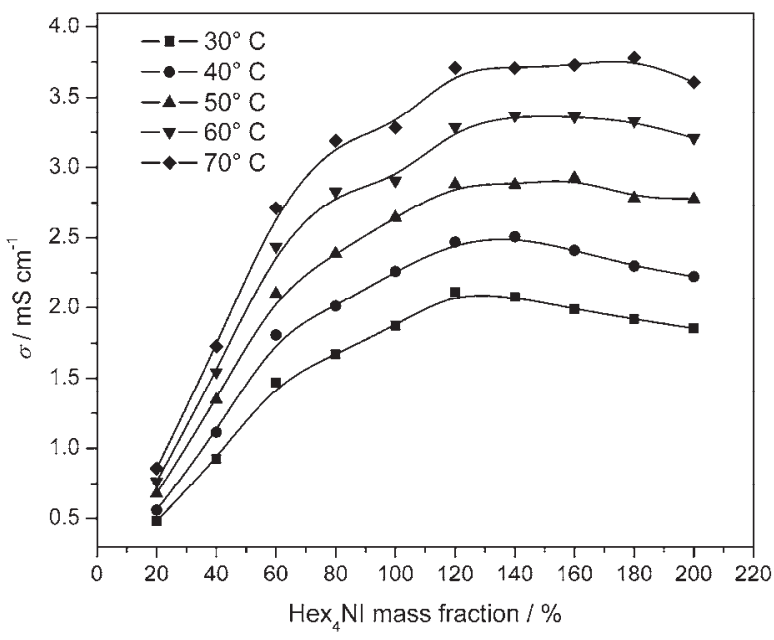

Figure 3: Conductivity as a function of $\mathrm{Hex}_{4} \mathrm{~N}^{+} \mathrm{I}^{-}$mass fraction $(x)$ with respect to PAN in PAN/EC/PC : $\mathrm{Hex}_{4} \mathrm{~N}^{+} \mathrm{I}^{-}$electrolyte at different temperatures.

In Figure 2, the fitted curves for high salt compositions are not shown as they lie close to each other and cannot be distinguished clearly from one another. Instead, only dotted lines connecting experimental points are shown as guides to the eye. The calculated activation energies $E_{\mathrm{a}}$ for all the samples shown in Table 1 are in the $0.15-$ $0.18 \mathrm{eV}$ range.

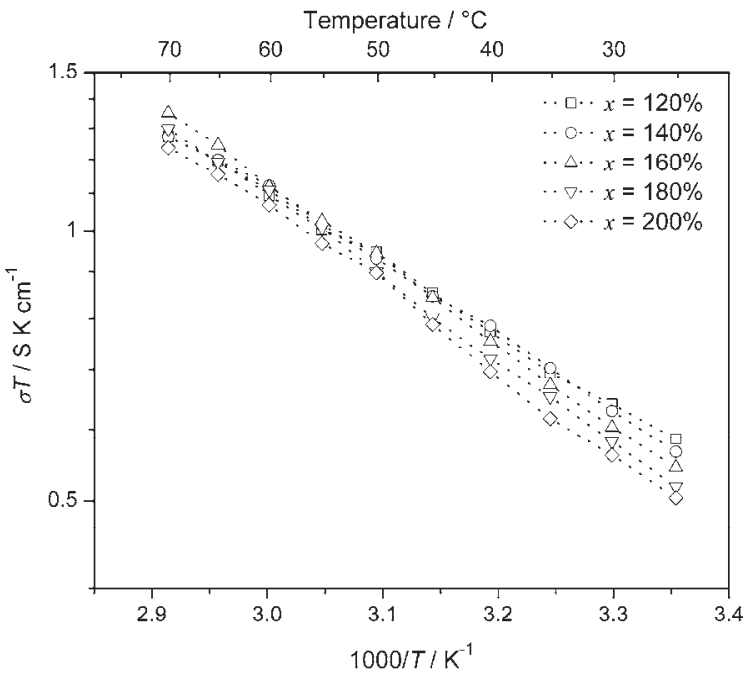

Figure 2: $\sigma T$ vs $1000 / T$ for PAN/EC/PC: $\mathrm{Hex}_{4} \mathrm{~N}^{+} \mathrm{I}^{-}$electrolytes containing $x$ wt $\%$ of $\mathrm{Hex}_{4} \mathrm{~N}^{+} \mathrm{I}^{-}$with respect to weight of PAN. The dotted lines shown are guides to the eye. Fitted lines to the Arrhenius equation are not shown.

Figure 3 shows the variation of ionic conductivity as a function of the mass fraction of the salt $(x \%)$ with respect to PAN at temperatures $30,40,50,60$, and $70{ }^{\circ} \mathrm{C}$. A conductivity increase is shown for the low salt composition more or less up to $120 \%$ salt mass fraction. However, a steeper conductivity increase is shown for low salt compositions up to about the $60 \%$ salt containing sample. This conductivity increase with added salt at low concentrations can be attributed essentially to an increase of the number of free ions due to ionic dissociation and to some extent from their mobility with the increasing amount of $\mathrm{Hex}_{4} \mathrm{~N}^{+} \mathrm{I}^{-}$. The less steep conductivity increase shown for salt mass fractions from $60-120 \%$ may be due to (a) the reduction of the number of free ions due to the formation of ion pairs and higher ionic aggregates; (b) the decrease in the ionic mobility caused by the increase in viscosity of the electrolyte medium. At $120 \%$ salt composition, the electrolyte shows the highest conductivity for lower temperatures and this sample gave the minimum conductivity activation energy as shown in Table 1. Hence, at higher salt concentrations, further addition of salt will not result in a conductivity increase. Several processes appear to be responsible for this trend. The decrease in mobility caused by the viscosity increase would have contributed to this behaviour along with the formation of a large number of ion pairs and higher ionic aggregates, which does not contribute to a further conductivity increase. In this concentration region nondissociated salt in the electrolyte may also block or limit 
Table 1: The activation energy- $E_{\mathrm{a}}$, and the glass transition temperature- $T_{\mathrm{g}}$, for electrolytes containing different mass fractions of, $x \mathrm{wt} \%$, of $\mathrm{Hex}_{4} \mathrm{~N}^{+} \mathrm{I}$

\begin{tabular}{rrrrrrrrrrr}
\hline $\mathrm{xwt} \%$ & 20 & 40 & 60 & 80 & 100 & 120 & 140 & 160 & 180 & 200 \\
\hline $\mathrm{E}_{\mathrm{a}} / \mathrm{eV}$ & 0.16 & 0.17 & 0.17 & 0.17 & 0.16 & 0.15 & 0.16 & 0.18 & 0.18 & 0.18 \\
$\mathrm{~T}_{\mathrm{g}} /{ }^{\circ} \mathrm{C}$ & -101.68 & -101.75 & -101.77 & -101.90 & -101.94 & -102.30 & -102.19 & -102.04 & -101.95 & -101.90 \\
\hline
\end{tabular}

the ionic mobility. These competing effects become clearer when the equivalent conductivity (molar conductivity) vs square root of salt concentration is plotted as shown in Figure 4. A somewhat similar analysis has been provided for other polymer electrolyte systems (Albinsson et al., 1993; Albinsson et al., 1994).

Figure 4 shows the graphs of equivalent conductivity (molar conductivity) vs square root of salt concentration for this gel electrolyte system. Interestingly, the equivalent conductivity shows a maximum at the $60 \%$ salt composition, whereas the conductivity maximum in Figure 3 is seen at the $120 \%$ salt composition. This clearly suggests that the ionic mobility starts to decrease from the $60 \%$ salt composition.

In order to explain the observed variation of molar conductivity vs square root of salt concentration $(\sqrt{C})$ shown in Figure 4, we will resort to the fact that these gel electrolytes are formed essentially by 'trapping' the $\mathrm{EC} / \mathrm{PC}$ based electrolytic solution in the matrix formed by PAN. PC is a solvent with low molecular weight and high dielectric constant. While the high dielectric constant favours salt dissociation, the low viscosity would lead to high ionic mobility in a pure $\mathrm{PC}$ based electrolytic solution at low salt concentrations. In the present gel electrolyte, the electrolytic solution is formed by dissolving the ionic salt $\mathrm{Hex}_{4} \mathrm{~N}^{+} \mathrm{I}^{-}$in the co-solvent ethylene carbonate (EC) and propylene carbonate (PC). Based on the above reasoning, we would expect the conducting properties of the gel electrolyte system in the present study to be determined essentially by the properties of the electrolytic solution at all concentrations.

As seen from Figure 4, at low salt concentrations up to about $60 \mathrm{wt} \%$ of $\mathrm{Hex}_{4} \mathrm{~N}^{+} \mathrm{I}^{-}$, the molar conductivity shows only a very slight increase, although one expects this to remain essentially constant. An increasing molar conductivity at low salt concentrations had been reported for several other electrolyte systems in this concentration range (Sigvartsen et al., 1989; Albinsson et al., 1993). A common explanation for this effect is the formation of triple ions in this concentration region as originally proposed by Fuoss and Kraus (1933) for electrolytic solutions. Another possible explanation is that the ionic re-dissociation occurs in this concentration region thereby increasing the fraction of free charge carriers with concentration. An additional effect in the present gel electrolyte may come from lowering the $T_{\mathrm{g}}$ of the polymer, although this effect is expected to be very small as the interaction of the PAN matrix on ionic transport in this type of gel electrolytes is believed to be not so significant.

As discussed above, it is generally believed that the conductivities of the gel electrolytes incorporating these electrolytic solutions are determined to a large extent by the conductivities of the electrolytic solutions used. Therefore, based on the reasoning given for electrolytic solutions, the molar conductivity of the gel electrolyte system at higher salt concentrations would be determined to a large extent by the viscosity of the electrolyte medium and its dielectric constant. It is interesting to note the almost linear behaviour of molar conductivity drops with

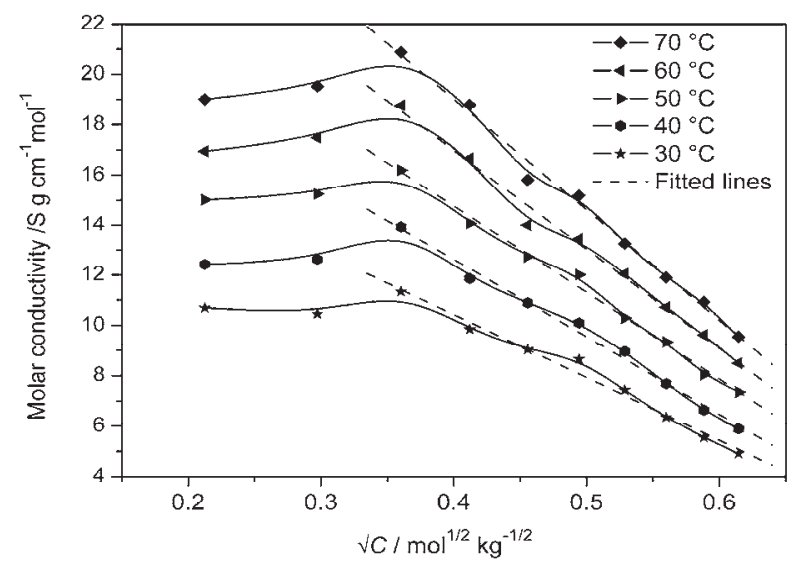

Figure 4: Molar conductivity as a function of square root of salt concentration in PAN/EC/PC: $\mathrm{Hex}_{4} \mathrm{~N}^{+} \mathrm{I}^{-}$electrolyte at different temperatures. Dotted lines represent fitted lines to the equation $\lambda=A_{1}-A_{2} \sqrt{C}$ for data in the high salt concentration region. 
increasing square root of salt concentration depicted in Figure 4 for salt concentrations higher than $60 \% \mathrm{Hex}_{4} \mathrm{~N}^{+} \mathrm{I}^{-}$. In the absence of simple conductance theories for high salt concentrations in electrolytic solutions or polymer electrolytes, we would attempt to use the conductanceviscosity relationship applicable to electrolytic solutions to explain the conductance behaviour in this region. A similar behaviour has been reported by Southall et al. (1996) to explain the observed molar conductance vs salt concentration in DMF- $\mathrm{LiCF}_{3} \mathrm{SO}_{3}$ and TG-LiCF $\mathrm{SO}_{3}$ liquid electrolyte systems. Both these organic solvents [N,N -dimethyl formaldehyde (DMF) and tetraethylene glycol dimethyl ether or Tetraglyme (TG)] are of low molecular weight and high dielectric constant, similar to $\mathrm{EC} / \mathrm{PC}$ co solvent used in the present work.

In order to analyze the data shown in Figure 4, it is considered that the charge transport in the gel electrolyte system predominantly occurs by the motion of anions $\left(\mathrm{I}^{-}\right)$and that the mobility of the counter ion $\left(\mathrm{Hex}_{4} \mathrm{~N}^{+}\right)$is negligible. The ionic conductivity may then be expressed as follows through the Nernst-Einstein equation,

$$
\sigma=n e^{2} D / k T
$$

where $D$ is the diffusion coefficient of the mobile species, $n$ is the number density of charge carriers, $e$ is the electronic charge and $k$ is the Boltzmann's constant. The diffusion coefficient is related to the viscosity of the electrolyte through the Stokes-Einstein equation,

$$
D=k T / 6 \pi r \eta
$$

where $r$ is the effective radius of the diffusing species. From the above two equations, one can relate the conductivity to the viscosity of the electrolyte medium as

$$
\sigma=n e^{2} / 6 \pi r \eta
$$

Comparing the conductivity and molar conductivity values for a given salt concentration at different temperatures (Figures 3 and 4), it can be seen that the number density of charge carriers, $n$, remains essentially unchanged with temperature for the entire composition range. Based on this, we expect the molar conductivity $(\sigma / n)$ to follow a reciprocal variation with viscosity with increasing salt concentration beyond $60 \%$. From the above analysis, it is clear that the almost linear drop in molar conductivity with salt concentration seen in Figure 4 for salt concentrations higher than $60 \% \mathrm{Hex}_{4} \mathrm{~N}^{+} \mathrm{I}^{-}$is very likely due to the increase of the viscosity of the electrolyte medium with the increase in salt concentration.
A detailed modelling of viscosity and conductivity for concentrated organic liquid electrolytes has been reported by Chagnes et al. (2002) for some lithium salts dissolved in gamma-butyrolactone. They were able to obtain a linear fit to molar conductivity $v s$ cube root of the concentration in the $0.1-1.6 \mathrm{M}$ concentration region. In the present study a linear drop of molar conductivity was observed with the square root of salt concentration in the concentration region of $0.13-0.38 \mathrm{kgmol}^{-1}$ and the data in this concentration region were fitted successfully to the empirical equation;

$$
\lambda=A_{1}-A_{2} \sqrt{C}
$$

where $A_{1}$ and $A_{2}$ are constants. The calculated values $A_{1}$ and $A_{2}$ are given in Table 2 for different temperatures.

Table 2: The values obtained for $A_{1}$ and $A_{2}$ by fitting to equation 5 at different temperatures.

\begin{tabular}{ccc}
\hline Temperature $/{ }^{\circ} \mathrm{C}$ & $\mathrm{A}_{1} / \mathrm{S} \mathrm{kg} \mathrm{m}^{-1} \mathrm{~mol}^{-1}$ & $\mathrm{~A}_{2} / \mathrm{S} \mathrm{kg}^{3 / 2} \mathrm{~m}^{-1} \mathrm{~mol}^{-3 / 2}$ \\
\hline 30 & 2.0 & -2.5 \\
40 & 2.5 & -3.1 \\
50 & 2.9 & -3.5 \\
60 & 3.3 & -3.9 \\
70 & 3.7 & -4.4 \\
\hline
\end{tabular}

The Debye-Huckle-Onsager theory can explain the conductivity $v s$ concentration behaviour of electrolytic solutions at low salt concentrations. A similar behaviour is expected for polymer gel electrolytes where an electrolyte solution is trapped by a polymer matrix, such as the gel system studied here. However, to our knowledge there is no accepted theory to explain the conductivity $v s$ concentration behaviour for electrolytic solutions or gel polymer electrolytes at higher salt concentrations. We believe that the present work would contribute towards a better understanding of these systems.

\section{DSC measurements}

Figure 5 shows the differential scanning calorimetric (DSC) thermograms of PAN/EC/PC: $\mathrm{Hex}_{4} \mathrm{~N}^{+} \mathrm{I}^{-}$electrolyte samples with different $\mathrm{Hex}_{4} \mathrm{~N}^{+} \mathrm{I}^{-}$mass fractions $(x \%)$ taken during the $2^{\text {nd }}$ heating run. The measurements of samples obtained during the $2^{\text {nd }}$ cycle were selected for this study in order to eliminate the effects of previous 
thermal history of the sample. In the DSC thermograms shown in Figure 5, a first order endothermic phase transition preceded by an exothermic cold-crystallization is observed, in particular for samples with more than $120 \%$ salt content. This can be attributed to the undercooling during the temperature decrease and thus a cold crystallization is followed by the crystallite melting of the EC rich phase.

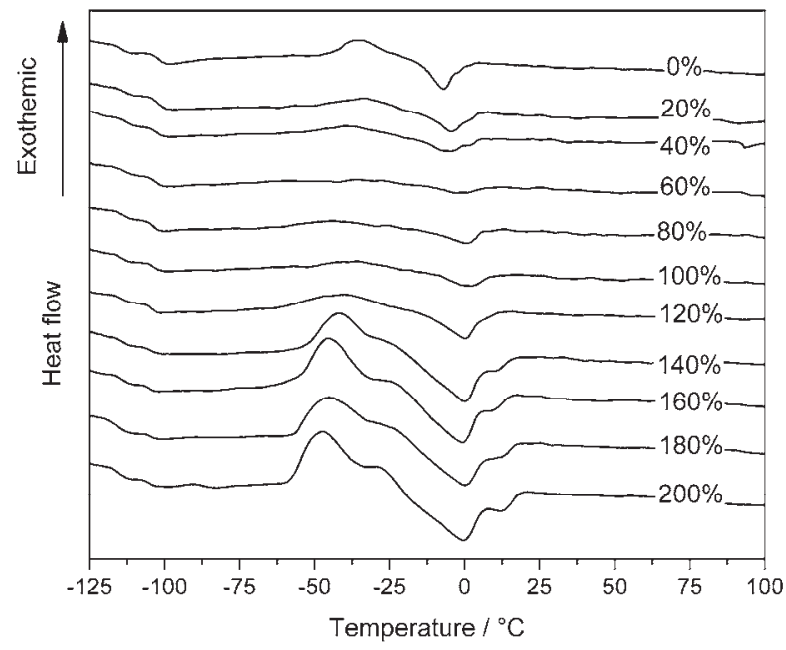

Figure 5: DSC thermograms of PAN/EC/PC polymer electrolytes containing $x$ wt $\%$ of $\mathrm{Hex}_{4} \mathrm{~N}^{+} \mathrm{I}^{-}$with respect to PAN weight under heating rate $10{ }^{\circ} \mathrm{C} \mathrm{min}^{-1}$.

A clear glass transition around $-102{ }^{\circ} \mathrm{C}$ can be observed for all the samples. The glass transition temperatures, $T_{\mathrm{g}}$, (mid point) obtained in this work using the $2^{\text {nd }}$ heating cycle are given in Table 1. According to reported literature for PAN/EC/PC gel electrolytes with other salts, the glass transition appears around $-100{ }^{\circ} \mathrm{C}$ (Jayathilaka et al., 2003).

In general, for most polymer electrolytes, the glass transition temperature $\left(T_{\mathrm{g}}\right)$ is related to the flexibly of the polymeric host material and the mobility of charge carriers (Tominaga et al., 2005; Wang et al., 2005). The minimum value $T_{\mathrm{g}},-102.3{ }^{\circ} \mathrm{C}$ was observed for the electrolyte containing $120 \mathrm{wt} \% \mathrm{Hex}_{4} \mathrm{~N}^{+} \mathrm{I}^{-}$and as expected this salt concentration gives the maximum conductivity. However, the conductivity increase shown in Figure 3 can be caused by both the increasing number of mobile ions as well as by the increase of mobility caused by an increase of segmental flexibility of polymer chain. A liquid-like charge transport mechanism where the liquid electrolyte is trapped in polymer cages has been suggested for this kind of PAN based electrolytes (Jayathilaka et al., 2003; Ileperuma et al., 2011). However, the present $T_{\mathrm{g}}$ data shows that there can be an appreciable contribution from the flexibility of the polymer matrix to the conductivity, since the variation of $T_{\mathrm{g}}$ in the present system is in agreement with the observed conductivity variation with the composition shown in Figure 3.

It is interesting to observe the somewhat unusual behaviour in the DSC thermograms of this gel electrolyte system in the temperature range of $-75^{\circ} \mathrm{C}$ to $25^{\circ} \mathrm{C}$ as a function of salt concentration. The melting peak, which is observed in this temperature range and evidently associated with the melting of EC or EC-rich phase in the electrolyte, could be seen very clearly in the gel polymer without $\mathrm{Hex}_{4} \mathrm{~N}^{+} \mathrm{I}^{-}(0 \%$ trace). This EC melting peak has diminished when the salt is added up to about $60 \%$ salt concentration and then disappeared almost completely at $60 \%$ composition. Then a slight re-appearance is visible for salt concentrations up to $120 \%$. Above $120 \%$, the transition peaks become more significant, may be related to the increase of ion association. The salt, apparently, first 'suppresses' the melting of EC-rich phase and then 'releases' it again with the increase in salt concentrations. We have also calculated the heat of enthalpy associated with this phase transition and observed that the heat of enthalpy follows a similar trend by exhibiting a jump as the salt concentration passes the $120 \%$ value.

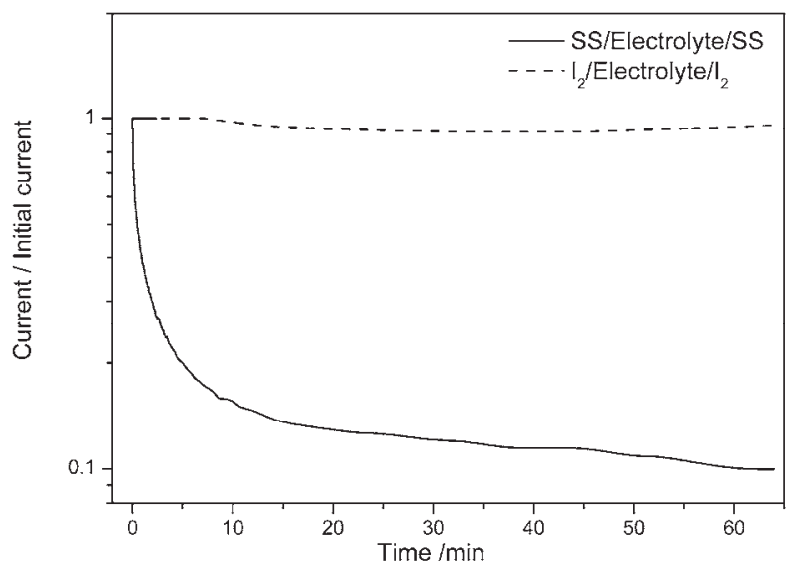

Figure 6: Current/initial current $v s$ time plot for the PAN/EC/PC: $\mathrm{Hex}_{4} \mathrm{~N}^{+} \mathrm{I}^{-}$electrolyte sample containing $120 \%$ salt mass fraction with respect to PAN taken from DC polarization measurements at $25{ }^{\circ} \mathrm{C}$. Solid line and dotted line are corresponding to the $\mathrm{SS} /$ Electrolyte/SS and $\mathrm{SS} / \mathrm{I}_{2} /$ Electrolyte $/ \mathrm{I}_{2} / \mathrm{SS}$ configurations, respectively. 


\section{DC polarization measurements}

DC polarization measurements (Ileperuma et al., 1988; Watanabe et al., 1988) obtained for the electrolyte sample containing $120 \%$ salt using $1.0 \mathrm{~V}$ bias voltage at $25{ }^{\circ} \mathrm{C}$ is shown in Figure 6 . When SS/electrolyte/SS configuration was used with stainless steel blocking electrodes, a steep current drop is observed within the first 10 minutes and the current subsequently reached to an approximately steady value after about 60 minutes. This suggests that the gel electrolyte is predominantly an ionic conductor with negligible electronic conductivity (Ileperuma et al., 2002). DC Polarization measurements in the SS/ $\mathrm{I}_{2} /$ electrolyte/I/SS symmetrical configuration with nonblocking iodine pellet electrodes showed no appreciable current drop with time during the measured time period. This ensures that the gel electrolyte is predominantly an iodide/triodide ion conductor.

\section{Solar cell characterization}

The $V-I$ characteristic curve for the quasi solid-state cells fabricated with configuration ITO/dye sensitized $\mathrm{TiO}_{2} /$ electrolyte/Pt coated ITO is shown in Figure 7. For this cell the gel electrolyte with 120 wt $\% \operatorname{Hex}_{4} \mathrm{~N}^{+} \mathrm{I}^{-}$/ $\mathrm{PAN} / \mathrm{EC} / \mathrm{PC}$ electrolyte and the dye sensitizer ruthenium 535-bis TBA were used. The short-circuit photocurrent density $\left(J_{\mathrm{SC}}\right)$ and open-circuit voltage $\left(V_{\mathrm{OC}}\right)$ of the cell are $8.1 \mathrm{mAcm}^{-2}$ and $0.79 \mathrm{~V}$, respectively under the irradiation of $1000 \mathrm{Wm}^{-2}$. The power density $v s$ cell potential is also shown in Figure 7. The maximum output power density, $31 \mathrm{Wm}^{-2}$ is shown at the current density $J_{\text {opt }}=6.6 \mathrm{mAcm}^{-2}$ and at the voltage $V_{\text {opt }}=0.47 \mathrm{~V}$. The short circuit current density, $8.1 \mathrm{mAcm}^{-2}$ is rather a good value compared to other quasi sold-state solar cells reported using quaternary ammonium iodide salts and ruthenium dye complexes (Ileperuma et al., 2002, 2004; Li et al., 2006). This higher current density in our system can be attributed to high iodide ion conductivity in the electrolyte due to the bulky $\operatorname{Hex}_{4} \mathrm{~N}^{+} \mathrm{I}^{-}$cation.

The fill factor and efficiency of the cell is calculated using;

$$
f f=\frac{J_{\mathrm{opt}} V_{\mathrm{opt}}}{J_{\mathrm{SC}} V_{\mathrm{OC}}}
$$

and

$$
\eta=\frac{J_{\mathrm{SC}} V_{\mathrm{OC}} f f}{\text { Total incident power density }}
$$

The fill factor of the cell is $48.5 \%$ and the overall energy conversion efficiency of the cell is $3.1 \%$. The rather poor fill factor of the cell that led to low efficiency could possibly be due to the $\mathrm{TiO}_{2}$ photoelectrode, which was fabricated in a very simple way without attempting to optimize it by minimizing the electron hole recombination. The main emphasis of this study was to optimize the electrolyte material. We believe that optimizing the $\mathrm{TiO}_{2}$ photo-anode and selecting a better dye sensitizer can help in improving the cell efficiencies.

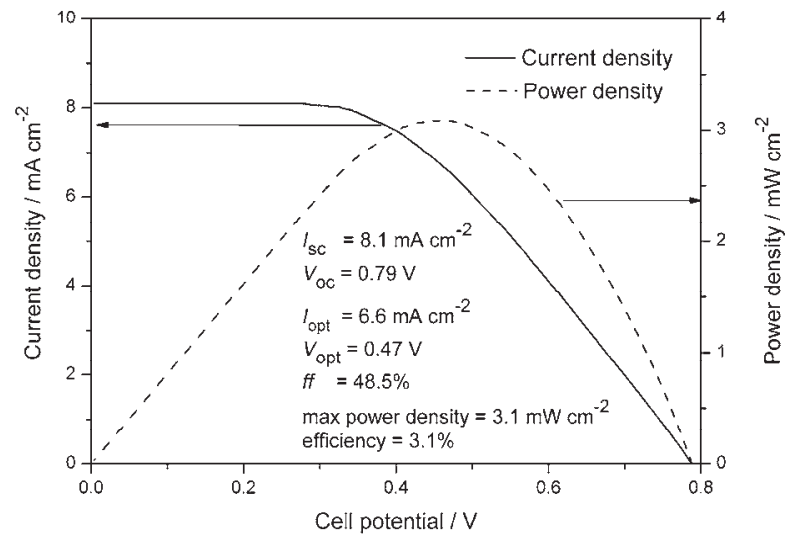

Figure 7: Photocurrent $v s$ cell potential difference curves for the DSSC fabricated using PAN/EC/PC electrolyte containing $120 \mathrm{wt} \% \mathrm{Hex}_{4} \mathrm{~N}^{+} \mathrm{I}^{-}$under irradiation of a $1000 \mathrm{~W} \mathrm{~m}^{-2}$ Xenon lamp.

\section{CONCLUSION}

Gel type polymer electrolyte films based on PAN host polymer was prepared by incorporating the salt, $\mathrm{Hex}_{4} \mathrm{~N}^{+} \mathrm{I}^{-}$and plasticizers EC and PC. The electrolyte containing $120 \%$ salt with respect to PAN weight showed the maximum conductivity out of the samples measured. This optimum conductivity electrolyte showed $2.0 \times 10^{-3} \mathrm{Scm}^{-1}$ conductivity at $25^{\circ} \mathrm{C}$ with a low $T_{\mathrm{g}}$ value of $-102.3{ }^{\circ} \mathrm{C}$.

The linear drop of molar (equivalent) conductivity with the square root of the concentration at salt mass fraction above $60 \% \mathrm{Hex}_{4} \mathrm{~N}^{+} \mathrm{I}^{-}$in the concentration region from $0.13-0.38 \mathrm{molkg}^{-1}$, is evidently governed by the increase in viscosity of the electrolyte medium. As inferred from the DC polarization tests, these gel electrolytes are predominantly iodide ion conductors with negligible electronic conductivity. DSC thermograms 
of the gel electrolyte system showed a rather unusual behaviour of the melting peak of the EC rich phase as the salt concentration is increased. Dye sensitized solar cells fabricated using this electrolyte showed $3.1 \%$ energy conversion efficiency and $8.1 \mathrm{mAcm}^{-2}$ of short circuit current density under irradiation of $1000 \mathrm{Wm}^{-2}$. It should be possible to further improve the cell efficiency by optimizing the photo-anode using better fabrication methods.

\section{Acknowledgement}

Research support from the National Research Council Sri Lanka (NRC 11-196), IPPS Uppsala and the Swedish Research Council is gratefully acknowledged.

\section{REFERENCES}

1. Abbott D. (2010). Keeping the energy debate clean: how do we supply the world's energy needs? Proceedings of the IEEE 98(1): $42-66$. DOI: $h$ ttp://dx.doi.org/10.1109/JPROC.2009.2035162

2. Albinsson I., Mellander B-E. \& Stevens J.R. (1993). Ion association effects and ionic conductivity in polymer electrolytes. Solid State Ion 60: 63 - 66. DOI: http://dx.doi.org/10.1016/0167-2738(93)90275-8

3. Albinsson I., Mellander B-E. \& Stevens J.R. (1994). Ion conductivity, electrical relaxation and ion association in poly (propylene glycol) complexed with ammonium triflate. Solid State Ion 72: 177 - 182.

DOI: http://dx.doi.org/10.1016/0167-2738(94)90144-9

4. Armand M.B., Chabagno M.J. \& Duclot M.J. (1979). Fast Ion Transport in Solids (ed P. Vashishta, J.N. Mandy \& G.K. Shenoy). Elsevier, New York, USA.

5. Bandara T.M.W.J., Dissanayake M.A.K.L., Albinsson I. \& Mellander B-E. (2010a). Dye-sensitized, nano-porous $\mathrm{TiO}_{2}$ solar cell with poly(acrylonitrile): $\mathrm{MgI}_{2}$ plasticized electrolyte. Journal of Power Sources 195(11): 3730-3734. DOI: http://dx.doi.org/10.1016/j.jpowsour.2009.11.148

6. Bandara T.M.W.J., Ekanayake P., Dissanayake M.A.K.L., Albinsson I. \& Mellander B-E. (2010b). A polymer electrolyte containing ionic liquid for possible applications in photoelectrochemical solar cells. Journal of Solid State Electrochemistry 14(7): 1221 - 1227.

DOI: http://dx.doi.org/10.1007/s10008-009-0951-x

7. Bandara T.M.W.J., Dissanayake M.A.K.L., Albinsson I. \& Mellander B-E. (2010c). Dye sensitized solar cells with poly(acrylonitrile) based plasticized electrolyte containing MgI . Electrochimica Acta 55 (6): 2044 - 2047. DOI: http://dx.doi.org/10.1016/j.electacta.2009.11.031

8. Chagnes A., Carre B., Willmann P. \& Lemordant D. (2002). Modeling viscosity and conductivity of lithium salts in gamma-butyrolactone. Journal of Power Sources 109(11): $203-213$.

DOI: http://dx.doi.org/10.1016/S0378-7753(02)00073-3

9. Chiba Y., Islam A., Watanabe Y., Komiya R., Koide N. \&
Han L. (2006). Dye-sensitized solar cells with conversion efficiency of $11.1 \%$. Japanese Journal of Applied Physics 45 (25): L638-L640.

DOI: $h$ ttp://dx.doi.org/10.1143/JJAP.45.L638

10. Dissanayake M.A.K.L., Bandara L.R.A.K., Bokalawala R.S.P., Jayathilaka P.A.R.D., Ileperuma O.A. \& Somasunderam S. (2002). A novel gel polymer electrolyte based on polyacrylonitrile (PAN) and its application in a solar cell. Materials Research Bulletin 37(5): 867 - 874. DOI: $h t t p: / / d x$.doi.org/10.1016/S0025-5408(02)00712-2

11. Fuoss R.M. \& Kraus C.A. (1933). Properties of electrolytic solutions. IV. the conductance minimum and the formation of triple ions due to the action of coulomb forces. Journal of the American Chemical Society A 55: 2387 - 2399. DOI: http://dx.doi.org/10.1021/ja01333a026

12. Gill D.S. (1979). Evaluation of solvated radii of ions in nonaqueous solvents. Electrochimica Acta 24: $701-703$. DOI: http://dx.doi.org/10.1016/0013-4686(79)87054-1

13. Hagfeldt A., Boschloo G., Sun L., Kloo L. \& Pettersson H. (2010). Dye-sensitized solar cells. Chemical Reviews 110: $6595-6663$. DOI: http://dx.doi.org/10.1021/cr900356p

14. Ileperuma O.A., Dissanayake M.A.K.L. \& Somasundaram S. (2002). Dye-sensitised photoelectrochemical solar cells with polyacrylonitrile based solid polymer electrolytes. Electrochimica Acta 47: 2801 - 2807.

DOI: $h$ ttp://dx.doi.org/10.1016/j.solmat.2004.02.040

15. Ileperuma O.A., Dissanayake M.A.K.L., Somasunderam S. \& Bandara L.R.A.K. (2004). Photoelectrochemical solar cells with polyacrylonitrile-based and polyethylene oxidebased polymer electrolytes. Solar Energy Materials and Solar Cells 84: 117 - 124.

DOI: http://dx.doi.org/10.1246/cl.2008.36

16. Ileperuma O.A., Kumara G.R.A. \& Murakami K. (2008). Quasi-solid polymer electrolytes based on polyacrylonitrile and plasticizers for indoline dye sensitized solar cells of efficiency 5.3\%. Chemistry Letters 37(1): $36-37$. DOI: http://dx.doi.org/10.1016/j.jphotochem.2010.10.024

17. Ileperuma O.A., Kumara G.R.A.,Yang H-S. \& Murakami K. (2011). Quasi-solid electrolyte based on polyacrylonitrile for dye-sensitized solar cells. Journal of Photochemistry and Photobiology A: Chemistry 217: $308-312$. DOI: http://dx.doi.org/10.1016/S0013-4686(02)00166-4

18. Jayathilaka P.A.R.D., Dissanayake M.A.K.L., Albinsson I. \& Mellander B-E. (2003). Dielectric relaxation, ionic conductivity and thermal studies of the gel polymer electrolyte system PAN/EC/PC/LiTFSI. Solid State Ion 156: $179-195$.

DOI: http://dx.doi.org/10.1016/S0167-2738(02)00616-1

19. Li B., Wang L., Kang B., Wang P. \& Qiu Y. (2006). Review of recent progress in solid-state dye-sensitized solar cells. Solar Energy Materials and Solar Cells 90: 549 - 573. DOI: http://dx.doi.org/10.1016/j.solmat.2005.04.039

20. Shen X., Xu W., Xu J., Liang G., Yang H. \& Yao M. (2008). Quasi-solid-state dye-sensitized solar cells based on gel electrolytes containing different alkali metal iodide salts. Solid State Ion 179: 2027 - 2030.

DOI: http://dx.doi.org/10.1016/j.ssi.2008.06.027 
21. Shimizu A. \& Taniguchi Y. (1990). NMR studies on reorientational motion of hydrated $\mathrm{D}_{2} \mathrm{O}$ molecules in tetraalkylammonium bromide dilute aqueous solutions. Chemical Society of Japan 63: 3255 - 3259.

DOI: $h$ ttp://dx.doi.org/10.1246/bcsj.63.3255

22. Sigvartsen T., Gestblom B., Noreland E. \& Songstad J. (1989). Conductometric and dielectric behaviour of solutions of tetrabutylammonium perchlorate in solvents of low and medium permittivity. Acta Chemica Scandinavia 43: $103-115$.

DOI: http://dx.doi.org/10.3891/acta.chem.scand.43-0103

23. Southall J.P., Hubbard H.V.S.A., Johnston S.F., Rogers V., Davies G.R., McIntyre J.E. \& Ward I.M. (1996). Ionic conductivity and viscosity correlations in liquid electrolytes for incorporation into PVDF gel electrolytes. Solid State Ion 85 (1-4): $51-60$.

DOI: http://dx.doi.org/10.1016/0167-2738(96)00040-9

24. Stephan M. (2006). Review on gel polymer electrolytes for lithium batteries. European Polymer Journal 42(1): $21-42$.

DOI: http://dx.doi.org/10.1016/j.eurpolymj.2005.09.017

25. Tennakone K., Senadeera G.K.R., Perera V.P.S., Kottegoda I.R.M. \& Silva L.A.A.D. (1999). Dye-sensitized photoelectrochemical cells based on porous $\mathrm{SnO}_{2} / \mathrm{ZnO}$ composite and $\mathrm{TiO}_{2}$ films with a polymer electrolyte. Journal of Materials Chemistry 11: 2474 - 2477.

DOI: http://dx.doi.org/10.1021/cm990165a
26. Tominaga Y., Asai S., Sumita M., Panero S. \& Scrosati B. (2005). A novel composite polymer electrolyte: effect of mesoporous $\mathrm{SiO}_{2}$ on ionic conduction in poly(ethylene oxide)-LiCF $\mathrm{SO}_{3}$ complex. Journal of Power Sources 146: $402-406$.

DOI: http://dx.doi.org/10.1016/j.jpowsour.2005.03.035

27. Wang Y-J., Pan Y., Wang L., Pang M-J. \& Chen L. (2005). Conductivity studies of plasticized PEO-Lithium chlorateFIC filler composite polymer electrolytes. Materials Letters 59: $3021-3026$.

DOI: http://dx.doi.org/10.1016/j.matlet.2005.05.011

28. Watanabe M., Nagano S., Sanui K. \& Ogata N. (1988). Estimation of $\mathrm{Li}+$ transport number in polymer electrolytes by the combination of complex impedance and potentiostatic polarization measurements. Solid State lon 28-30: 911 - 917.

29. Wright P.V. (1975). Electrical conductivity in ionic complexes of poly (ethylene oxide). British Polymer Journal 7(5) : $319-327$.

DOI: http://dx.doi.org/10.1002/pi.4980070505

30. Wu J., Lan Z., Wang D., Hao S., Lin J., Huang Y., Yin S. \& Sato T. (2006). Gel polymer electrolyte based on poly(acrylonitrile-co-styrene) and a novel organic iodide salt for quasi-solid state dye-sensitized solar cell. Electrochimica Acta 51: 4243 - 4249. DOI: http://dx.doi.org/10.1016/j.electacta.2005.11.047 